\title{
Forensic Medicine Curriculum in Medical Schools of Malaysia- A review
}

\author{
Dr Shetty Charan Kishor
}

\begin{abstract}
Every medical graduate has to compulsorily serve the government in Malaysia, before he can be a duly registered medical practitioner with the Malaysian Medical Council, in order to practise within Malaysia. During the course of his service as a Government Medical Officer, he is required to undertake medico-legal examinations of living and medico-legal autopsy of the dead relating to common offences, etc. These medical examinations are required by law for dispensing justice, as per the Penal Code, and other laws common to Malaysia and other former British Colonial countries of south Asian region. However the undergraduate Forensic Medicine curriculum has been progressively whittled down through repeated amendments of the undergraduate syllabus on the lines followed in some of the more developed nations. The latter have adequate post-graduate qualified Forensic experts in each district to undertake these tasks, and do not require the medical graduate to undertake these onerous and difficult examinations in their districts. This reduction of the under-graduate Forensic syllabus has resulted in many of the graduates not being given exposure to the minimal content necessary to undertake these examinations. They are thus uninitiated and unaware of the various situations and their responsibilities where they may be required to undertake these examinations for corroborating a crime or proving the innocence of a suspect examined. This paper lays emphasis on the legal expectations and also about standardization of forensic medicine curriculum for undergraduate medical degrees in Malaysian medical schools.
\end{abstract}

Key Words: Forensic Medicine, Medical practitioner, Legal Expectations, Medico-legal autopsy, Clinical Forensic Medicine

\section{Introduction}

In Latin, forensis means of the forum, and many propose this to be the origins of the term Forensic Medicine. Historically, Forensic Medicine was earlier known as Medical Jurisprudence (though today Medical Jurisprudence usually alludes to Legal aspects of Medical Practise including Law in relation to Medical Men). In some countries it is still known as Legal Medicine and in certain cases, State Medicine. ${ }^{1,2}$

The word Forensic is a derivative of Modern western medical science. It derives its origin from the practice of the ancient Greek in bringing disputes, including those involving the infliction of injuries and the apportioning of blame for causing those injuries, and/or compensation, to the "forum". This latter function of determining who caused the injuries and/or the extent of damages liable was the responsibility of the assembled publicans (senators) and elders, the persons invested with civic and legal responsibilities is not unlike our modern judiciaries with jurors. ${ }^{1,2}$

\section{Current Forensic Medicine Curriculum in Medical Schools in Malaysia}

Most medical schools in this country do provide teaching of

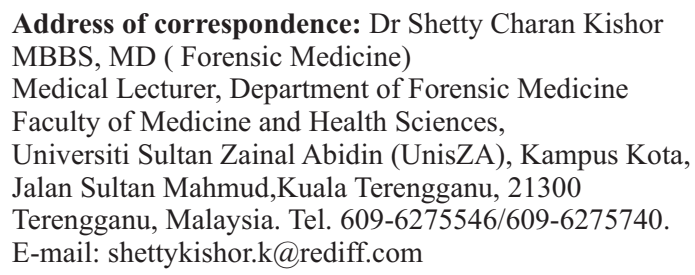

forensic Medicine in their curriculum. However further scrutiny on the curriculums, revealed the following issues that need to be raised.

The Forensic Medical curriculum has been markedly reduced. Some medical schools only provide a few lectures only whilst others are more, ranging from a few hours lectures to about 2 weeks forensic block or modules. It is commendable that the majority taught the subject during 4 th year Medicine.

There are also non uniformity on the course contents, most medical schools emphasized only on the Forensic Pathology courses such as Autopsy practice and determining death and topics on types of injuries pertaining to the dead bodies. The application of Clinical forensic Medicine has not been addressed at all in the Forensic Medicine Curriculum of most medical schools.

Moreover because of the perception that this subject is part of Pathology, some medical schools allow it to be taught by Pathologist instead of specialist in Forensic Medicine. Thus the clinical forensic topics such as Forensic Medical Examination of Sexual Assault victims, suspects of crimes and evidence management has been omitted or not included.

Some medical schools should be commended, providing comprehensive theoretical lectures hours or small group discussions on topics in Forensic Medicine. But there are no emphasis and no exposure at all on the practical parts of the subject. There are no provisions in some of these schools for post mortem experience and "mock trial" or "Moot court" session. In Malaysia, the requirement for the medical graduate, working as a Government Medical Officer, is to be

Bangladesh Journal of Medical Education 2014;5(1):2-5. C 2014 Kishor, publisher and licensee Association for Medical Education. This is an Open Access article which permits unrestricted non-commercial use, provided the original work is properly cited. 
well versed in the medico-legal situations and problems encountered in his day-to day practise in Government service and their solutions. This also extends to the diagnosis and management of poisoning and its proving, if discovered as a cause of death. He may also be called upon to examine and report on many other situations such as the juvenile offenders and instances of injuries to children, etc. to the 'Protector' of custody cases, ${ }^{38}$ as well as immigrants brought for examination, to establish that they are not harbouring any communicable or infectious disease, under the Immigration Act.

However, due to the designing of the undergraduate syllabus on the pattern of western undergraduate syllabi, this aspect of undergraduate teaching is accorded least priority. Forensic Medicine in fact faces the first onslaught in the deletion of teaching man-hours, so that not even the bare essence of Forensic Pathology, Ethics or Toxicology is being taught, so that there is no question of further creating awareness of the clinical aspects of Forensic Medicine.

\section{Legal expectations from the Malaysian Medical Graduate. $^{3-35}$}

Any medical graduate, after graduating has to provisionally register, to undergo the necessary training, so as to have his/her name entered in the register of medical practitioners within the country, as required by the Medical Act (Malaysia) 1971. For this purpose, he/she has to first apply to the registrar, Malaysian Medical Council, to be provisionally registered, for the sole purpose of obtaining the experience required for full registration ${ }^{4}$. He can register by thus applying, provided that he/she has a recognised M.B.B.S. or equivalent degree, as listed in the Second schedule. Otherwise after the candidate passes a prescribed test for this purpose, the Minister, after consultation with the Medical Council, would deem that his/her degree in medicine and surgery is suitable for registration. This is done if the candidate produces evidence that he/she has been selected for employment in an approved hospital or institution in Malaysia for a period of not less than one year, in medicine and surgery in a resident posting. ${ }^{5}$

After provisional registration, on the satisfactory completion of this resident medical posting, he/she would be awarded a certificate to this effect viz. that he/she has satisfactorily completed the compulsory resident medical posting.

An applicant having qualifications other than those in the schedule, and applying for registration after the approval of the Minister, and after clearing the prescribed qualifying test, would have to continue in service in a medical resident capacity, to the satisfaction of the Director General, for a further period of not less than two years in such post/s, as directed to serve at Director General's discretion.

The Medical Council may exempt him/her from this additional resident posting, on the basis of the applicant's further qualifications, if they feel that the person has the experience which is not less in scope and character that that prescribed, when they may exempt the applicant from the further 2 years of service. ${ }^{6}$ After the satisfactory completion of the resident medical posting, he/she will again be entitled to a certificate to this effect. ${ }^{2}$

Only a person who has satisfactorily completed the requirements as mentioned in the previous paragraph, by being provisionally registered and having served in a resident medical capacity, can apply to be fully registered as a medical practitioner in Malaysia. ${ }^{7}$ During this period of compulsory government service, while provisionally registered, he would be deemed to have been fully registered under the Act, so as to undertake employment and service successfully. ${ }^{8} \mathrm{He}$ shall also be considered as a public servant within the meaning of the Penal Code, ${ }^{9}$ thus requiring him/her to carry out all the duties and bear all the responsibilities incumbent upon such a person.

Only fully qualified practitioners are entitled to carry on the practise of the speciality they are registered as qualified in, or to charge or recover through any court of law - reasonable fees for his services, or visitations, etc. ${ }^{10}$ The later is possible provided he/she has a valid annual practising certificate at that time, and is the only one whose signature on a certificate or document required by any written law is considered to be valid" $^{11}$. Wherever the word "legally qualified medical practitioner" or "duly qualified medical practitioner" features in any testimony or statement, it is understood that it connotes a fully registered medical practitioner, for this purpose $^{12}$.

\section{Standardization of Forensic Medicine Curriculum for Undergraduate Medical Degrees in Malaysian Medical Schools. ${ }^{36-40}$}

This paper seeks to propose to the medical schools authorities to implement a minimal standard of Forensic Medicine Course in their curriculum.

1. Forensic Medicine must be taught to all medical students. It is recommended that either during the 4th Year or 5 th Year medical undergraduate training.

2. The subjects should be taught by specialist or lecturers with recognized Forensic Medicine qualifications. It should be a separate subject from Pathology. There should also be enough topics in Clinical Forensic Medicine and Medical Jurisprudence included in the curriculum.

3. It is proposed that a minimum of 2 weeks or equivalent period should be put for teaching in Forensic Medicine. And further 1 week practical post mortem examination exposure in Autopsy Suites or mortuaries. At least 5 cases should be selected as case write ups or reports and assessed by the supervisors or lecturers. Failing to provide the case write ups or reports may bar the students from advancing to the final year or sitting the final examination. Alternatively an end of block or end of course formal examination may be conducted, failing the examination, the student must sit for a remedial and 
must passed the examination before they can proceed to the final year. A proposed time table containing the recommended topics and hour lectures, small group discussions, seminar and practicals is attached below.

4. There should be an end of block or module assessment or examination included after the course. The students should be assessed by the qualified lecturers/specialist in Forensic Medicine.

5. Those universities that lack lecturers in Forensic Medicine are encouraged to recruit Forensic Medicine Specialist (Forensic Pathologist) in the Ministry of Health of Malaysia as part time or honorary lecturers. These specialists should be invited to coordinate and formalized the Forensic Medicine curriculum, not just merely giving lectures.

6. There are some teaching hospitals, where the numbers of autopsies are not that many for the whole 1 week period; this is in particular those hospitals in the east coast and north of the peninsular. The students could be arranged to the other hospitals identified with heavier workloads, for example, UIAM medical students are send to the main hospitals in the West Coast such Hospital Kuala Lumpur, Hospital Selayang, Hospital Serdang, Hospital Tengku Ampuan Rahimah Klang, Hospital Sultanah Aminah Johor Bharu, Hospital Tengku Jaafar Seremban, Hospital Tengku Bainun Ipoh, Hospital Pulau Pinang and Hospital Alor Setar for the 1 week practical training on autopsies. The students are also allowed to attend autopsy cases during the whole period of their clinical training in the particular hospitals, as long as they can accumulated at least 5 autopsy cases before they proceed to the final year.

7. The Clinical Forensic practical experience is more difficult, due to the sensitivity and security nature of the cases. Since the examination involved highly sensitive patients such as victims or survivors of sexual assault, victims of violence and suspects of crimes. The suspects of crimes brought by police may be suspects of homicides or other "serious arrest able offences" and are often heavily guarded by the police or wardens, their forensic examination require safety and security issues in hospitals. The actual demonstration of examination may not be possible in many of these cases, however the students may be exposed with these cases by video demonstration and also during the clinical rotation at the Emergency Department whenever the cases available at the hospital's One Stop Crisis Centre or at the Examination Room in the hospitals.

\section{Conclusion}

The curriculum of Forensic Medicine should have proper orientation of the student towards recognising cases of foul play, and the various forms of suspicious or unnatural deaths. A reasonable idea of how to go about proving this through a post-mortem examination, or clinical examination and reporting when these living cases are presented for medico-legal documentation, should have been imparted to the undergraduate student as part of his training.

The doctor-to-be should be familiar with the process and procedures of death investigations and the importance of solving medicolegal problems surrounding any death through an adequate post-mortem examination. They should also be able to recognise and manage medico-legal evidences collected during clinical examination and proper medical a report writing when presented with living patients for medico-legal examination. All these important and relevant medico-legal knowledge should have been imparted to the undergraduate students as part of their training so as to ensure the provision of a safe and quality forensic medicine services to the public when they are registered as a medical practitioner.

They should also be initiated in the processes of laws they would be dealing with in their day-to-day existence, and the role of medical men in various situations where the law calls on them to assist it. The medical graduate should be able to recognise in time- poisons and poisoning and their management; various ethical aspects of practise and malpractice suits arising out of their (medical) duties/practise, - and their defence against them.

They should be conversant with their role in a trial proceeding in court, the norms in evidence giving /taking in any investigation or trial, and an overview of the legal system they will be part of, to name a few. Some hands-on experience towards making of a medico-legal report of a living- injured patient and post-mortem examination should also be envisaged, so that in the long run, the graduate does not suffer from lack of adequate teaching and training, when called upon to undertake these duties when assigned to him. Only then can we claim to have prepared the Malaysian medical graduate for the duties and tasks before him when he begins to serve his compulsory 2 to 3 years' government service as the Government Medical Officer. This is especially so in relation to medico-legal cases brought to him by the police, etc. according to the prevalent laws in force.

\section{Conflict of interest}

The author has no conflict of interest to declare.

\section{Acknowledgment}

The author is thankful to Department of Forensic Medicine, Faculty of Medicine and Health Sciences, Universiti Sultan Zainal Abidin (UnisZA), Kampus Kota, Jalan Sultan Mahmud, Kuala Terengganu, 21300, Terengganu, Malaysia for encouraging research and its publication in international journals.

\section{References}

1. Sahu S C. History of Forensic Medicine, Ch II, in Franklin C A. Ed Modi's Textbook of Medical Jurisprudence and Toxicology, 21st ed. Bombay: N.M. Tripathi Pvt. Ltd.; 1988;. 20-27. 
2. Paul G. Teaching Of Undergraduate Forensic Medicine In The Malaysian Medical Curriculum And The Medico-Legal Responsibilities Of The Malaysian Medical Graduate. Anil Aggrawal's Internet Journal of Forensic Medicine and Toxicology, 2000; Vol. 1, No. 2 (July-Dec 2000): http://www.anilaggrawal.com/ ij/vol_001_no_002/paper008.html; Published: September 2, 2000, (Accessed: May 28, 2014).

3. Evidence Act 1950 (Act 56) Sec. 45, 46.

4. Medical Act 1971, Part III; sec12(1).

5. Medical Act 1971, Part III; sec 13 (2).

6. Medical Act 1971, Part III; sec 13 (6).

7. Medical Act 1971, Part III; sec 14.

8. MedicalAct 1971, Part III; sec 13 (7).

9. MedicalAct 1971, Part III; sec 13 (8).

10. Medical Act 1971, Part III; sec 26.

11. Medical Act 1971, Part III; sec 27.

12. Medical Act 1971, Part III; sec 28.

13. Criminal Procedure Code (F.M.S. Cap. 6), Part VIII; sec 328.

14. Criminal Procedure Code (F.M.S. Cap. 6), Part VIII; sec 330.

15. Criminal Procedure Code (F.M.S. Cap. 6), Part VIII; sec 331.

16. Criminal Procedure Code (F.M.S. Cap. 6), Part VIII; sec 332.

17. Criminal Procedure Code (F.M.S. Cap. 6), Part VIII; sec 328.

18. Penal Code (F.M.S. Cap. 45), Ch II; sec. 44

19. Penal Code (F.M.S. Cap. 45), Ch XVI; sec. 319.

20. Penal Code (F.M.S. Cap. 45), Ch XVI; sec. 320.

21. Penal Code (F.M.S. Cap. 45), Ch XVI; sec 321,323; 322,$325 ; 327 ; 328 ; 329 ; 330 ; 331 ; 332 ; 333 ; 334 ; 337$; \& 338.

22. Criminal Procedure Code (F.M.S. Cap. 6), Part I, Ch 1, sec 2; Part III, Ch IV. Sec 23.

23. Penal Code (F.M.S. Cap. 45), Ch XVI, sec 307.
24. Penal Code (F.M.S. Cap. 45), Ch XVI, sec 308.

25. Penal Code (F.M.S. Cap. 45), Ch XVI, sec 375, 376.

26. Penal Code (F.M.S. Cap. 45), Ch XVI, Sec 377A-C.

27. Penal Code(F.M.S. Cap. 45), Ch IV; Sec 85.

28. Penal Code (F.M.S. Cap. 45), Ch. VI; Sec. 300.

29. Penal Code (F.M.S. Cap. 45), Ch IV; sec 86.

30. Penal Code (F.M.S. Cap. 45), Ch VI; sec 328.

31. The Code of Criminal Procedure, 1973 (Act No. 2 of 1974), India. Ch XII; sec 174-176.

32. Criminal Procedure Code (Act No. 2 of 1974) sec. 53.

33. Criminal Procedure Code (Act No. 2 of 1974) sec. 54.

34. Penal Code (F.M.S. Cap. 45), Ch IV; sec 269.

35. Penal Code (F.M.S. Cap. 45), Ch IV; sec 354, 509.

36. Murty OP, Pillay VV, DabasCB, Sarangi MP, Paul G. Medical Education : Curriculum of Undergraduate and Postgraduate Courses in Forensic Medicine \& Toxicology, International Journal of Medical Toxicology \& Legal Medicine, July -Dec, 1998 1:1; 25 30

37. The Perugia Document, Teaching Legal Medicine to Medical Undergraduate students, European Council of Legal Medicine, Cologne, 1992.

38. Mant AK. The decline in the teaching of legal medicine. BMJ 1986; 293:1390.

39. Goode AW, Cameron JM. Looking to the past for the sake of the future. Med Sci Law 1998; 40:2-3.

40. Knight B, Thompson I. The teaching of legal medicine in British medical schools. Med Educ 1986;20:246-58.

*Corresponding author and requests for clarifications and further details:

\section{Dr Charan Kishor Shetty}

Medical Lecturer

Department of Forensic Medicine

Faculty of Medicine and Health Sciences

Universiti Sultan Zainal Abidin (UnisZA), Kampus Kota

Jalan Sultan Mahmud,Kuala Terengganu, 21300

Terengganu, Malaysia. Telephone no. 609-6275546/609 6275740.

Bangladesh Journal of Medical Education 2014;5(1):2-5. 